\title{
Comorbidity Index
}

National Cancer Institute

\section{Source}

National Cancer Institute. Comorbidity Index. NCI Thesaurus. Code C19253.

In epidemiology, a rating scale for comorbidity. 